\title{
Metaphor in Action in Political Discourse
}

\author{
Lin Xu \\ Dept.of Politics, Bengbu Automobile NCO Academy, Bengbu 233011, China \\ 1234567@163.com
}

Keywords: Metaphor, Function, Political Discourses.

\begin{abstract}
More and more metaphors are employed in different patterns of discourses, especially in political discourses. Politics is inseparable with metaphors. This thesis makes an analysis of the functions of metaphors in political discourses from three aspects, namely, the stylistic function, the cognitive function and the social function. Vivid expression, succinct wording, clear meaning and easy understanding contribute to the stylistic function of metaphors in political discourses. For the cognitive function, metaphors have the function of guiding perception, structuralizing experience and creating new insight. The social function is that through the use of metaphors, a political discourse may easily inform people by stirring their emotions. Metaphors can serve as a persuasive device in political discourses and debates. Also, metaphors can create a sense of consolidation among people and thus mobilize people into the war. In addition, metaphors may deceive people by disguising or embellishing something.

Metaphor and politics are closely interwoven. Graber once said that political communication is the "lifeblood or mother's milk of politics because communication is the essential activity that links the various parts of society together and allows them to function as an integrated whole" (Graber, 1993:305). As Edelman (1977) contended, at the core of political communication is the ability of the politician to use metaphor and symbols that awaken potential tendencies among the masses.
\end{abstract}

\section{Language and Culture}

To understand the relationship between language and culture, first we'd better to make clear what is language and culture. Language is an arbitrary and sound symbol system of human beings (Wardhaugh,1972; Hu Zhuanglin et.al,1988). Language is a tool for communication which is language's primary function. Language can deliver cognition, relationship, management, law, economy, military, culture,etc. It is language that put people together to constitute the society.

Language can also be used to describe the world (Xu Guozhang,1991). People use names to distinguish different things. Obviously, people can not recognize and describe the world without language. Language is the container and carrier of culture(Xu,1991). People know the world, accumulate experiences and knowledge by coexisting with and struggling with the nature. Experience and knowledge are expressed, stored and exchanged by language. That is why we gain knowledge by reading and learning and it's not necessary for us to experience all things by ourselves. On the country, it we have to experience things to gain knowledge, the development of knowledge will be restricted.

Culture can be categorized into two aspects - broad aspect and narrow aspect. As to the broad aspect, culture is defined as the feature of human beings. Any characteristics between people and nature are contained in the culture category. So we can say culture is all-inclusive. With regard to the narrow aspect, culture is a complicated entirety including knowledge, belief, art, moral, law, custom, capability, habits acquired by human beings as social numbers (Tylor, 1920).

Just like language, only human beings have culture which is the production of people's cooperation. Culture is a social phenomenon which emphasizes the contrast between society and nature. Culture is also the national phenomenon, because each nation has its unique geography, history and establishes and develops its own culture. No two cultures in the world are same. 
Language is a part of culture and it is also the carrier and container of the culture. We use language to describe, explain and analyze. In this case, language is the mirror of culture (Wang Zhenya,2004). Language is affected and restricted by culture and also language affects culture.

\section{Metaphor and Culture}

Sometimes, we find people unconsciously use metaphors in their public discourse. But, we will feel puzzled by some of the metaphors, because we don't have the cultural knowledge behind them. Such a fascination and amazement have led me to a close examination of people's use of metaphor.

Metaphors are widely used in human communication, ancient or contemporary, formal or informal. It is not just a matter of choice of expressions nor is it merely a rhetorical device or a linguistic convenience in human communication. Metaphor participates fully in the process of knowledge and brings us a new world.

Culture is the symbol of civilization and the development of human language is closely related to diversities of culture. Different cultures may cause people to use different metaphors. For example, Western people tend to use obviously more sports, business, and driving metaphors, because they consciously or unconsciously view their life as sport and business; while Chinese appear to use far more frequently family, eating and performing metaphors. So we can say language and culture are closely related. Being a figure of speech, metaphor must be simultaneously influenced by and actively influencing culture. In some senses, metaphor is a culture product and the use of metaphor is largely according to culture. In that way, speakers' worldviews and behavior can be revealed and shaped by metaphor.

On most occasions, Western people are fond of using sports and business metaphors, which reflect the features of people's experience, thinking and vision. Most probably, speakers of one language find it difficult to appreciate the metaphors of another language. This is because "communication is based on the same conceptual system that we use in thinking and acting"(Lakoff \& Johnson, 1980: 3). In that case, individuals who do not live in the same established world or speech community will sometimes possess rather different conceptual systems and will in turn find each other's metaphors sometimes difficult to understand. We can say the use of metaphors is universal, and the choice of specific metaphor to describe things is culture-related. Just as many scholars have shown, language is a culture product. Understanding the differences and having more studies can help us gain a better and much deeper comprehension and appreciation of speakers of other languages and seek more effective communication with them.

\section{Metaphor and Language}

Metaphor is not only a figurative speech used in literal works, but also a way of communication. Metaphor is the reflection of people's way of thinking. Lakoff and Johnson find that metaphor is pervasive in everyday life, not just in language but in thought and action. Our ordinary conceptual system, in terms of which we both think and act, is fundamentally metaphorical in nature (Lakoff \& Johnson,1980:3). So we can say our language is metaphorically thinking.

\section{Sports Metaphor in Political Discourse}

Western people view their life as sport and think and act accordingly. Whether it is politics, business, or even personal relationships, it is a game for them to win. Politicians fight and compete with their opponents in order to win an election. Business people have to beat their competitors to survive. Even in daily communication, activities and personal relationships, people are playing games. In other words, people frequently talk about their activities in terms of sports: baseball, boxing, football, etc. It is so common that the word race is more often used than the term "election campaign" and the phrase "running mate" sounds far more familiar than that of someone's "campaign partner." 
Since sports metaphors are so popular in American English, we can see that in the American conceptual system, sports, business and politics are always combined. American people have obsession with sports. People fuse politics and sports, showing people's perception of life as sports without awareness of it. We can use Lakoff and Johnson's words to demonstrate the reason,

Our conceptual system is not something we are normally aware of. In most of the little things we do every day, we simply think and act more or less automatically along certain lines. Just what these lines are is by no means obvious. One way to find out is by looking at language. Since communication is based on the same conceptual system that we use in thinking and acting, language is an important source of evidence for what that system is like. (1980:3)

We may ask how the connection of politics and sports contribute to Americans' conceptual combination of the two domains. Since the United States is the nation with high democracy, everyone is encouraged to participate in governing, so politics is widely concerned about by Americans. Only sports can compete with politics in term of popularity and the extent and level of participation. Most people agree that American sports, especially professional sports, are the products of industrialization and sports have in turn strengthened the political industry. Politics and sports constantly promote and benefit from each other.

Sports are a good way to promote national pride and patriotism. There's no wonder that lots of politicians turn to sports for various political purposes. For instance, many city mayors are willing to spend a great amount of money to keep a ball club in the city. Politics and sports are conceptually combined and the image of politicians and that of sport stars are inclined to merge. People hope their sports stars become politicians and politicians are good at sports.

Since sports are closely related to politics, Americans even regard sports starts as heroes. In the government, there are quite a few politicians who were professional players. American children are taught to possess the spirit of competition, self-reliance, and entrepreneurship. This conception gradually forms the foundation of American way of life. People seek free competition and enterprise.

In the public discourse, sports and politics always coexist and many politicians often unconsciously take politics as sports. We can say that American politics is in a sense a sports game. By utilizing sports metaphors, politics can be clearly depicted as a contest between two opponents. Sports metaphors can explain an electoral system in which one side seeks to defeat the other. Also, sports metaphors can function to create an image of play in politics like " they first have to run for and win the office in election", "to play and score points in political or legislature games" and "fight the opposition while in office." In short, these metaphors are deeply rooted in American culture and appeal widely to the American electorate.

\section{War Metaphors in Political Discourse}

The use of the metaphor as a description for all human activities, especially war is very popular in modern political world. We can find in political speeches, war metaphors are often utilized. Many of the concepts in political domain are structured by the concept of war. A number of entailments of the war metaphor are quite appropriate for politics. War almost always has some goal, some purpose for the activity. It is common for warring nations to establish war aims in a highly formal way.

Not every one directly experiences the war but almost all of us are familiar with the concept of war. Strategy is a key entailment. The word strategy is taken from the military arts. Actually, there are lots of similarities between the strategy consideration of an army at war and those of a political enterprise. Just as in war, the business leader assesses his own situation, his strengths and weaknesses; he judges the opponent's position, strengths and weakness; and he thinks through the opportunities that are presented and the threats that must be dealt with. Many people are even fond of everything with respect to wars. The general situation is that two armies confront each other and fight against each other due to different reasons. One side tries to beat and win over the other side using the force, weapons and strategies. There are attack, counterstrike, defend, violence, damage, wins and loses in the war. 
Generally speaking, the cognition and understanding of political operation and mechanism are structured by the conception of war. Politicians who employ the war metaphor must view themselves in the role of the commander. There are some positive aspects to this role. The image of a great war leader conjures up associations of high competence, moral strength, and the ability to inspire and lead men. The positive aspects of the metaphor are its entailments of risk and difficulty and the need for outstanding leadership. These are all good fits to the experience of politics. The need for strategy development has also been a helpful idea that politics has generally adopted from warfare.

Since metaphors and cultures are closely connected, war metaphors have their cultural origins. War has influence on language, because the social consciousness affects human society greatly. To some extent, culture is a kind of social ideology and the meaning of language has close relationship with that ideology. Through language, people's thoughts are exchanged, their intensions are realized, and the important experience of their existence is recorded. From war to social value, and from social value to language, we have the conclusion that war has fundamental influence on the language. This influence can be demonstrated in the following two aspects: expressions in war concept are extraordinarily abundant and subtle; all kinds of expressions in that concept are ready to map into other concepts. Although the means of debates, ballgames, trade competitions and love affairs is not violent, it has the same purpose with war-to force enemies to obey our will. So these concepts easily absorb war vocabulary to rich their expressions.

Lakoff and Johnson put forward the metaphorical concept-argument is war, in which "argument" is target domain and "war" is source domain. It is a very classic metaphor. People often use lots of words related to war to describe different situations in arguments, such as attack every weak point in one's argument, win an argument, shoot down one's arguments, etc. The appearance of these expressions is due to the fact people structure the concept of argument with the war concept. Actually people also structure other concepts with the war concept. There are some examples here:

Example 1: The wars among several big markets are emerging.

Actually, in the above sentence, "war" is source domain, and "competition" is target domain. Competition among the markets is very severe and it must lead to cruel results - some winners and some losers. Although the war among markets is not full of smoke of gunpowder and the smell of blood, it is still fierce.

Example 2: Currently we'd better take no actions to lower the price but wait our enemies to make attack first so as to make clear of their strategy.

Here "actions" is source domain, while "measures" is target domain. "Taking actions" used in battles means to do something to change or advance the process of the battle. In the above sentence, the phrase means the managers will not utilize any methods to change the situation.

Example 3: The telecom operators have started a furious war to strive for customers.

The more customers a telecom operator can gain, the more profits he can get. So the contest like a war among the telecom operators is intense.

Example 4: The cars of VW have occupied the majority of the market to become the industry leader.

In the battlefield, one side will try its best to occupy the other side's territory and it is the symbol of victory. The word "occupied" used in the above sentence is one of the vocabulary in the conceptual system of wars and it is used for the description of business competition.

Example 5:They're the real victims of the competition.

"Victims" in the last sentence means "losers" in the competition. They haven't gained any benefits and instead they lose money. In that case, they are "victims".

Example 6: Though our competitions are defeated this time they still possess strong force.

In the war, if one side has failed, we call it is "defeated". While the competition is like the war in which some one must succeed and some one fail. "Strong force" means we still have the ability to succeed in future. 
The italicized words "wars, take no actions, start a furious war, occupy, victim, defeat, strong force" are all the vocabularies in the conceptual system of wars and they are utilized in political discourses. Conceptualizing competition in terms of war has become so commonplace today.

\section{Stylistic Function of Metaphors in Political Discourse}

Metaphor not only reflects but also shapes our conceptual system. It is often through the metaphorical process that human beings conceptualize the world and construct reality. Kovecses(1999) argues and shows that to understand things alien or new, human beings always first resort to metaphor.

Metaphors may be used for daily political activities such as reporting meeting or political negotiation for mass mediums such as TV, newspaper and broadcast, etc. Although they are used in different styles, serve for different purposes and try to achieve different effects and objectives, they have common features of style. We get precise, suitable and excellent expression and description by the application of metaphors. These metaphors used in political field appear in reports, newspapers, magazines, TV programs, broadcast, etc. Most probably, people may not realize metaphors are widely used in political discourse and they think political discourses need seriousness, strictness. Actually, metaphors can serve different aims to reach good effects.

When a political discourse is delivered, the speaker or writer hopes that his listeners or readers can understand the information conveyed. But the problem is that because of their limited background of political knowledge, they can't comprehend the essence of the discourse. Political phenomena and activities are often so complicated that they are composed of a large number of abstract ideas and notions, which are rather difficult for most people to understand. Thus the speaker has a good idea that many abstract notions in political discourse are expressed by metaphorical concepts in order to reach aimed effect. The language of political discourses should be clear, concise and succinct. If the language of political discourse is wordy and tortuous, it may cause misunderstanding and can't achieve the effect. Also, the discourse full of unclarity and vagueness can't attract people's attention and people may lose interest.

Comprehension is a complicated process of grasping the meaning of a language or a person. It is based on the intelligence, sympathy and cultural background and related to how we perceive things and situations around us. Good comprehension also needs experience of the world. A metaphoric model is a way to structure the knowledge of the target domain by mapping onto its concepts and relations from an existing source domain that is already familiar. Political phenomena, activities consist of a lot of abstract ideas and notions, which are too difficult for most people to understand easily. If the politicians use many difficult vocabularies and very professional expressions to describe these abstract ideas, notions, the audience will feel puzzled. In order to make audience fully understand the contents, many metaphorical concepts are used widely in political discourse. "Metaphors have also been understood as a shorthand to transform meaning and to understand new, unknown things by attaching them to older, known things" (Mclnnis 1984:109) Since most of the political notions are too abstract for understanding, metaphors can help to connect abstract things with life experiences.

Metaphorical concepts help people understand one abstract concept in terms of another concrete concept. Thus a successful metaphor really plays an important role in making difficult discourse easier to understand. It is an explanatory device which gets the complex and abstract issues absorbed into people's way of thinking. It is also a way of simplifying the difficulties and solving the problems.

In political discourse, cooperation and alliance among groups or countries are often mentioned. The cooperation and alliance among countries have different situations and their forms are diversified, sometimes difficult for us to make clear of. But we can understand it by metaphor "love match", and the following table can make it clearer: 
Table 1: Mapping between marriage relationship and alliance

\begin{tabular}{|l|l|}
\hline $\begin{array}{l}\text { Source Domain: } \\
\text { love and marriage relationship }\end{array}$ & $\begin{array}{l}\text { Target Domain: } \\
\text { merger or alliance }\end{array}$ \\
\hline lovers & countries, nations, parties \\
\hline courtship & negotiations \\
\hline engagement & signing the contract \\
\hline marriage & establishment of alliance \\
\hline divorce & cold relationship \\
\hline parents & leadership \\
\hline
\end{tabular}

These conceptual elements obviously do not cover all concepts from the love-marriage domain. Rather, they form conceptual clusters that focus on a few aspects of "common-sense" knowledge and experience of "love" relationships. Our knowledge of love and marriage is mapped onto the knowledge of political activities.

Example 1: The two international groups fall in love with each other and will sign the cooperation contract as soon as possible.

Example 2: The alliance finally broke since it wasn't a love match at the beginning.

Example 3: With the bankruptcy of one party the marriage of several years has come to the end.

Because people know the process of marriage and some of them have had the experience of wedding, they understand the metaphors easily, especially for those people who perceive the whole process of people's love and have similar cultural background. People who experienced the process of breakup or divorce would understand the relationship between parties more fully and they may feel sympathetic about the situations. For those people who have become parents, they can understand the real meaning of leadership and try to explore how to maintain it or even to make it more powerful.

The metaphors really change the abstract concepts into the concrete and tangible entity. With these familiar entities and concepts we have no difficulty in understanding the target abstract notions. So metaphors are a good means for us to understand discourses easily.

\section{Summary}

Metaphors play a very important stylistic role in political discourses. From the above analysis, metaphors' stylistic functions are mainly divided into four categories, which are closely connected. Vivid expression can make description more concise and clear. Succinct wording is helpful for the clear description. Vivid expression and succinct wording help to make the meaning more clear so that the discourse is easy to understand. Only when the four aspects are well combined, can political discourses achieve the best effect.

\section{References}

[1] Aristotle. Rhetoric and Poetics. New York: The Modern Liberty, 1954.

[2] Black, M. Models and Metaphors. Itaka: Cornell University Press, 1962.

[3] Black, M. More about Metaphor. In A. Ortony (ed.), Metaphor and Thought, Cambridge: ambridge University Press, 1979.

[4] Chilton, P. \& Iiyin, M. "Metaphor in Political Discourse: the Case of the European House" Discourse and Society 4(1993):7-31. 